\title{
Influence of Harvest Intervals on Growth Responses and Fatty Acid Content of Purslane (Portulaca oleracea)
}

\author{
Desmond G. Mortley ${ }^{2}$ \\ G.W. Carver Agricultural Experiment Station, Tuskegee University, 214 \\ Milbank Hall, Tuskegee, AL 36088
}

\begin{abstract}
Jun-Hyun Oh and Damicca S. Johnson ${ }^{1}$
Department of Plant and Food Sciences, Sangmyung University 300 AnseoDong, Dongnam-Gu, Cheonan, Chungnam, 330-720, South Korea
\end{abstract}

Conrad K. Bonsi and Walter A. Hill

G.W. Carver Agricultural Experiment Station, Tuskegee University, 214 Milbank Hall, Tuskegee, AL 36088

Additional index words. polyunsaturated fatty acid, linoleate, linolenate, greenhouse plant growth

\begin{abstract}
A greenhouse study was conducted to evaluate the influence of harvest intervals on biomass yield and omega fatty acids of 'Golden purslane' (Portulaca oleracea). Nutrients were supplied as a modified full-strength Hoagland solution two to three times weekly. Plants were harvested sequentially at 20, 40, and 60 days after transplanting (DAT) corresponding to 42, 63, and 84 days after sowing. Fatty acids were determined using a gas chromatography-mass spectrometry. Harvest intervals significantly influenced foliage fresh and dry weight, leaf number and plant height, and root length and fresh weight and were greatest at 60 DAT. Fatty acid analysis verified the presence of myristate, palmitate, linoleate, and linolenate at $20 \mathrm{DAT}$ and in all three harvests, whereas stearate and oleate were detected only in the last two harvests (40 and 60 DAT). Linoleate, palminate, and linolenate were the most abundant fatty acids in purslane with levels in excess of $300 \mathrm{mg} \cdot \mathrm{kg}^{-1}$. Those for myristate, stearate, and oleate were in excess of $200 \mathrm{mg} \cdot \mathrm{kg}^{-1}$. The ratio of omega-6/omega-3 ranged from 0.44 for Harvest 1 to 1.1 for Harvest 3, whereas ratios for harvest intervals two and three were equal to or greater than the recommended daily human requirement. Results showed qualitative and quantitative differences of harvest intervals of purslane, suggesting that an optimal ratio of omega- 6 to omega-3 fatty acids can be achieved $\approx 20$ DAT.
\end{abstract}

Purslane (Portulaca oleracea) is a member of the portulacaceae family and is an annual that produces hundreds of seeds that remain dormant until conditions are favorable for germination. Over the last 10 years, purslane has gained added attention as a result of the discovery that it possessed the highest content of omega-3 fatty acid among several green leafy and succulent vegetables such as spinach, red leaf lettuce, buttercrunch lettuce, or mustard greens (Alamazan and Adeyeye, 1998; Liu et al., 2000; Palaniswamy et al., 1997, 1998, 2001; Simopoulos, 2002). GuilGuerrero and Rodriquez-Garcia (1999) showed that leaves of purslane yielded a greater amount

\footnotetext{
Received for publication 9 Sept. 2011. Accepted for publication 17 Jan. 2012.

This research was supported by funds from USDA/CSREES Grant No. ALX-SP-1.

Contribution of the George Washington Carver Agricultural Experiment Station, Tuskegee University. ${ }^{1}$ Former Graduate Student.

${ }^{2}$ To whom reprint requests should be addressed; e-mailmortleyd@tuskegee.edu.
}

of lipids/100 g dry weight compared with other edible species.

There is a fair amount of variation in the lipid content of purslane based on time of harvest. For example, Omara-Alwala et al. (1991) reported that lipid content of purslane leaves and stems varied depending on harvest time [30, 49, or $59 \mathrm{~d}$ after planting (DAP)]. Palaniswamy et al. (2001) reported that the concentration of polyunsaturated essential fatty acids in the leaves of purslane harvested at six-, 10- and 14-true-leaf developmental stages (corresponding to 35,49 , and 60 DAP) varied significantly. They found a lower concentration of lipids at the 10-true-leaves stage vs. at six- or 14-true-leaf stages. They also reported differences with respect to the ratio of omega- 3 to omega- 6 regardless of stages of development.

Liu et al. (2000) also showed that leaves, stems, and seeds of Australian purslane were an excellent source of alpha linolenic acid compared with American varieties harvested at different stages of growth $(45,60$, or 70 DAP) regardless of whether plants were grown in the field or a greenhouse. Total fatty acids and alpha linolenic acid were greater in the seeds, whereas longer-chain fatty acids were not detected in any of the samples. These reports suggest that the amount of omega- 3 fatty acids in purslane depends largely on the developmental stage at which the plants are harvested as well as the plant parts analyzed.

There are several sources of omega- 3 fatty acids that are available commercially, including from fish and flax seed oils. However, these are relatively expensive to obtain and adequately consumed in proper dosages. Growing and consuming purslane would be a relatively inexpensive source of this essential fatty acid. There is limited information available concerning the content and form of omega- 3 and omega- 6 fatty acids present in purslane at intermediate harvest intervals.

Our objective was to evaluate the influence of sequential intermediate harvest intervals on growth responses and omega-3 fatty acid content of purslane.

\section{Materials and Methods}

Experiments were conducted in a greenhouse in a completely randomized design with three replications. Each replication contained three plots with 18 plants each. Seeds of 'Golden purslane' (Nicholas Garden Nursery, Albany OR) were sown in moist commercial Jiffy Mix (Batavia, IL) medium in TLC Pro-Trays transplant flats (TLC Polyform, Inc., Plymouth, MN) and covered with $\approx 0.6 \mathrm{~cm}$ of the medium. Flats were placed in a greenhouse, watered as needed, and seeds germinated after $3 \mathrm{~d}$. Seedlings were grown for $\approx 3$ weeks after which they were transplanted into greenhouse beds containing a 1:1:1 (v/v) mixture of Jiffy mix, sand, and soil. Seedlings were placed $20 \mathrm{~cm}$ within and $25 \mathrm{~cm}$ between rows totaling $\approx 18$ plants per plot. Plants were fertilized with a modified fullstrength Hoagland nutrient solution (Hoagland and Arnon, 1950) two to three times weekly supplying 84, 31, and $234 \mu \mathrm{g} \cdot \mathrm{g}^{-1}$ nitrogen, phosphorus, and potassium, respectively.

Greenhouse conditions included a 12-h light/12-h dark period by supplementing natural sunlight with cool white fluorescent lamps at sundown and a matching thermoperiod of $28{ }^{\circ} \mathrm{C}$ light $/ 22{ }^{\circ} \mathrm{C}$ dark cycle. Relative humidity was $50 \pm 5 \%$ and photosynthetic photon flux at canopy level averaged $300 \pm 25 \mu \mathrm{mol} \cdot \mathrm{m}^{-2} \cdot \mathrm{s}^{-1}$.

Fourteen plants each were sequentially harvested at 20, 40, and 60 DAT and separated into tops and roots. Both plant parts were placed under running tap water followed by two successive deionized water rinses to remove adhering soil. Shoots and roots were blot-dried on paper towels after which fresh weights were taken. Plant tissues were dried at $70{ }^{\circ} \mathrm{C}$ for $72 \mathrm{~h}$ and dry weights of component plant parts determined. Samples of shoots for gas chromatographic analysis were frozen and stored at $-80{ }^{\circ} \mathrm{C}$ before freeze drying for at least $24 \mathrm{~h}$ before analysis. After freeze drying, samples were ground to a fine powder in a Waring Commercial Laboratory Blender (Torrington, CT). 
A gas chromatograph linked to a mass spectrometer (Shimadzu, Osaka, Japan) was used to analyze for omega-3 fatty acids according to the method of Nielson (2003). A 0.5 -g sample was added to $5 \mathrm{~mL}$ of hexane and incubated at room temperature for $30 \mathrm{~min}$ on a shaker at $50 \mathrm{rpm}$ followed by centrifugation at $5000 \mathrm{rpm}$ for $10 \mathrm{~min}$ and filtered through a funnel containing $1 \mathrm{~g}$ of anhydrous sodium sulfate to remove excess water. Sodium methoxide reagent $(1.5 \mathrm{~mL})$ was added to the hexane solution and the mixture shaken for $1 \mathrm{~min}$ to methylate the fatty acids, to which $5 \mathrm{~mL}$ of $\mathrm{NaCl}$ solution was added. Before analyses, all samples were filtered to pass a $0.2-\mu \mathrm{m}$ filter to remove impurities. To identify peaks on the chromatogram, retention times, peak heights, and areas were compared with standard fatty acids as well as with those in the mass spectrometry library. Fatty acids were expressed as a percentage and compared with established standards (Nu-Chek Prep, Elysian, $\mathrm{MN})$. Data were combined by treatments and tested by analysis of variance using the General Linear Model procedure (SAS Institute, 2009) with significance determined at the 0.05 level of probability.

\section{Results and Discussion}

Harvest interval significantly influenced both above- and below ground biomass (Table 1). Foliage fresh and dry weight, number of leaves per plant, plant height, root length, and root fresh weight all increased substantially as plants matured and were highest at 60 DAT. These increases in biomass with harvest intervals are consistent with those reported by Palaniswamy et al. (2001); they characterized the developmental stages in terms of the appearance of true leaves rather than DAT.

At 20 DAT, four fatty acids were identified: myristate (C14:0), palmitate (C16:0), linoleate (C18:2), and linolenate (C18:3; Fig. $1)$, whereas six were identified at 40 and 60 DAT (stearate C18:0 and oleate C18:1) inclusive of the four identified at $20 \mathrm{DAT}$. Five of the fatty acids increased substantially with harvest intervals. However, myristate (C14:0) remained virtually unchanged between 40 and 60 DAT. All the fatty acids except myristate (C14:0) increased an average of 1.5- to 2.5fold from 20 to 60 DAT. That myristate (C14:0), palmitate (C16:0), linoleate (C18:2), and linolenate (C18:3) were identified at 20 DAT suggests that they are apparently synthesized during early developmental stages, whereas stearate and oleate are synthesized during later stages of growth. Linoleate, palminate, and linolenate were the most abundant fatty acids in purslane with levels in excess of $300 \mathrm{mg} \cdot \mathrm{kg}^{-1}$. Those for myristate, stearate, and oleate were in excess of $200 \mathrm{mg} \cdot \mathrm{kg}^{-1}$ (Fig. 1).

Similar fatty acid profiles of purslane have been observed by others (Guil et al., 1996; Guil-Guerrero and Rodriguez-Garcia, 1999; Liu et al., 2000; Omara-Awala et al., 1991; Palaniswamy et al., 2001). Indeed, Palaniswamy et al. (2001) identified palmitate, stearate, oleate, linoleate, and linolenate in purslane leaves at different developmental stages (six-, 10-, and 14-true-leaf stages) but reported that the increase in fatty acids was not steady. In contrast, our results showed a steady increase in fatty acids from 20 to 40 DAT and substantial increases up to 60 DAT. Palaniswamy et al. (2001) used leaves, however, whereas we used the entire aboveground plant parts. Omara-Alwala et al. (1991) analyzed individual parts as well as whole plants and obtained fatty acid profiles, which decreased after the first harvest and subsequently increased at final harvest in every plant part, generally, except the stems. However, whereas Omara-Alwala et al. (1991) did not provide an explanation for their findings, Palaniswamy et al. (2001), who obtained similar results at the 10-true-leaf stage (49 DAT) compared with the six-true-leaf stage (35 DAT), suggested that this response could be attributable in part to a "dilution effect" or use of the fatty acids synthesized to repair cell damage as a result of oxidative stress. It is probable that because the 40 DAT harvest time used by both researchers was outside the range (49 DAT; 10-true-leaf stage) combined with the varying environmental conditions may have influenced responses of the plants.

The contents of major fatty acids, linoleate (C18:2; omega-6) and linolenate (C18:3; omega-3), increased significantly with harvest intervals (Fig. 2). At 20 DAT, the content of omega-3 (linolenate) was more than twice that of the omega- 6 (linoleate) fatty acid. The reason for this is unclear; however, Ezekwe et al. (1999) found a similar trend during their first harvest of purslane. The difference between omega- 6 and omega- 3 fatty acids was substantially reduced at 40 and 60 DAT but remained significant.

Although individual availability of both omega-6 and omega-3 in food can benefit human health significantly, extensive research results (Brown, 2004; Ezekwe et al., 1999; Klurfeld, 1998) have emphasized that the ratio at which they are present is equally important. In our study, the ratio of omege- 6 to omega- 3 fatty acids increased significantly between 20

Table 1. Foliage and root yield of purslane in response to harvest intervals.

\begin{tabular}{|c|c|c|c|c|c|c|}
\hline \multirow{2}{*}{$\begin{array}{l}\text { Harvest } \\
\text { interval (d) }\end{array}$} & $\begin{array}{l}\text { Foliage } \\
\text { fresh wt }\end{array}$ & $\begin{array}{c}\text { Foliage } \\
\text { dry wt }\end{array}$ & \multirow[b]{2}{*}{ Leaf no. } & Plant ht & $\begin{array}{l}\text { Root } \\
\text { length }\end{array}$ & \multirow[b]{2}{*}{ Root wt (g) } \\
\hline & \multicolumn{2}{|c|}{---------- (g) ---------- } & & \multicolumn{2}{|c|}{-------- $(\mathrm{cm})$-------- } & \\
\hline 20 & 1.5 & 0.45 & 11 & 4.8 & 9.4 & 0.10 \\
\hline 40 & 7.2 & 2.63 & 27 & 6.1 & 12.0 & 0.38 \\
\hline 60 & 27.2 & 15.28 & 69 & 9.3 & 18.6 & 0.81 \\
\hline Significance & $* *$ & $* *$ & $* *$ & $* *$ & $* *$ & $* *$ \\
\hline
\end{tabular}

**Significant at the 0.01 level of probability.

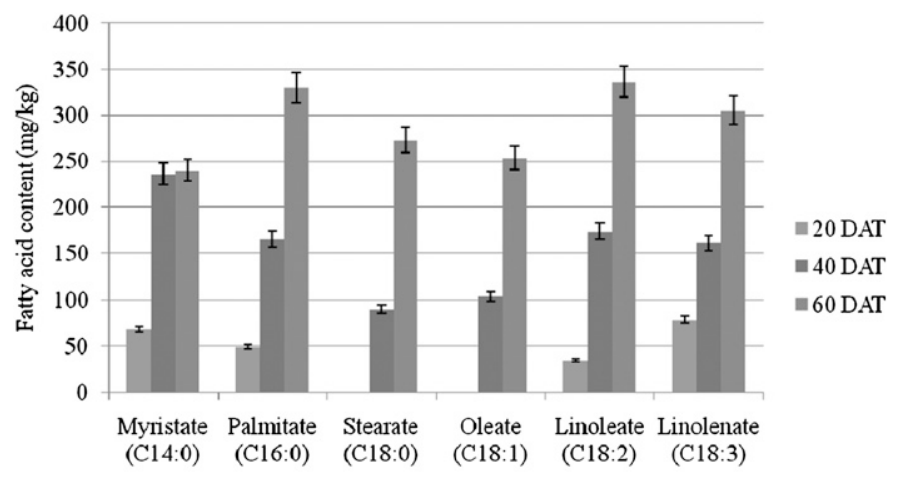

Fatty Acid

Fig. 1. Fatty acid contents of purslane in response to harvest intervals.

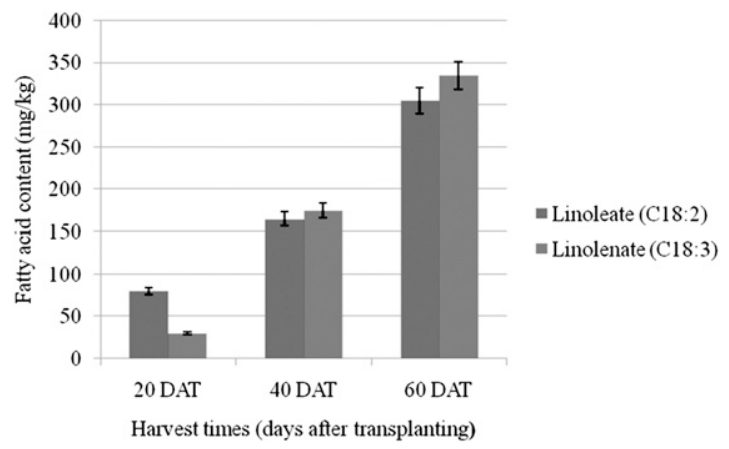

Fig. 2. Omega-3 and omega-6 fatty acid content of purslane in response to harvest intervals. 
and 40 DAT but was similar between 40 and 60 DAT, being 1.08 and 1.1, respectively (data not shown). Our results fall within the 1:1 to 1:7 ratio suggested by Klurfeld (1998).

The lower rates of coronary heart disease and cancer in populations consuming a higher ratio of omega- 6 to omega-3 fatty acids have been well documented (Thorsdottir et al., 2004; Youdin et al., 2000). It is generally agreed that the optimal ratio of omega- 6 to omega- 3 fatty acid for human diets ranges between 1:1 and $7: 1$ (Klurfeld, 1998) with healthy ratios ranging from 1:1 to 1:4 (Lands, 2005; Tribole, 2007). In fact, because most agricultural crops are richer in omega- 6 than omega- 3 fatty acids, increased intake of omega-3 from major crops may not be achieved. In the typical American diet, the ratio of omega- 6 to omega- 3 fatty acids is believed to range between 10:1 and 40:1 (Hibbeln et al., 2006) instead of the 1:1 to 7:1 ranges (Klurfeld, 1998; Lands, 2005; Tribole, 2007). Our data demonstrate that an optimal ratio of omega- 6 to omega- 3 fatty acids can be achieved as early as 20 DAT.

\section{Literature Cited}

Alamazan, A. and S. Adeyeye. 1998. Fat and fatty acid concentrations in some green vegetables. J. Food Compost. Anal. 11:375-380.
Brown, A. 2004. Understanding food: Principles and preparation. 2nd Ed. Wadsworth, Belmont, CA.

Ezekwe, M., T. Omara-Alwala, and T. Membrahtu. 1999. Nutritive characterization of purslane accessions as influenced by planting date. Plant Foods Hum. Nutr. 54:183-191.

Guil, J., M. Torija, J. Gimenez, and I. Rodriguez. 1996. Identification of fatty acid in edible wild plants by gas chromatography. J. Chroma. A. 719:229-235.

Guil-Guerrero, J. and I. Rodriguez-Garcia. 1999. Lipids classes, fatty acids and carotenes of the leaves of six edible wild plants. E. Food Res. Tech. 209:313-316.

Hibbeln, J.R., L.R. Nieminen, T.L. Blasbalg, J.A. Riggs, and W.E. Lands. 2006. Healthy intakes of n-3 and n- 6 fatty acids: Estimations considering worldwide diversity. Amer. J. Clin. Nutr. 83:1483S-1493S.

Hoagland, D.R. and D.J. Arnon. 1950. The waterculture method for growing plants without soil. California Agr. Exp. Stn. Circ. 347, Univ. of California, Berkeley, CA

Klurfeld, D. 1998. Dietary fats, eicosanoids and the immune system, p. 495-505. In: Akoh, C.C. and D.B. Min (eds.). Food lipids: Chemistry, nutrition and biotechnology. Marcel Dekker, Inc., New York, NY.

Lands, W.E.M. 2005. Fish, omega-3 and human health. 2nd Ed. AOCS Publ., Urbana, IL.

Liu, L., P. Howe, Y. Zhou, Z. Xu, C. Hocart, and R. Zhang. 2000. Fatty acids and $\beta$-carotene in
Australian purslane varieties. J. Chroma. A. 893:207-213.

Nielson, S. 2003. Food analysis laboratory manual. Springer-Verlag, New York, NY.

Omara-Alwala, T., T. Mebrahtu, D. Prior, and O. Ezekwe. 1991. Omega-three fatty acids in purslane tissues. J. Amer. Oil Chem. Soc. 68:198199.

Palaniswamy, U., R. McAvoy, and B. Bible. 1997. Omega-3 fatty acid concentration in Portulaca olerace $\mathrm{L}$. is altered by the source of nitrogen in hydroponic solution. HortScience 32:462-463.

Palaniswamy, U., R. McAvoy, and B. Bible. 1998. Omega-3 fatty acid concentration in Portulaca oleracea $\mathrm{L}$. is altered by the photosynthetic photon flux. HortScience 33:480.

Palaniswamy, U., R. McAvoy, and B. Bible. 2001. Stage of harvest and polyunsaturated essential fatty acid concentrations in purslane leaves. J. Agr. Food Chem. 49:3490-3493.

SAS Institute. 2009. SAS user's guide. Statistics, Version 9.2 edition. SAS Institute, Cary, NC.

Simopoulos, A.P. 2002. The importance of the ratio of omega-6/omega-3 essential fatty acids. Biom. Pharma. 56:365-379.

Tribole, E. 2007. The ultimate omega-3 diet: Maximize the power of omega-3s to supercharge your health, battle inflammation and keep your mind sharp. McGraw-Hill, New York, NY.

Youdin, K.A., A. Martin, and J.A. Joseph. 2000. Essential fatty acids and the brain: Possible health implications. Intl. J. Dev. Nuero. 18:383399. 